7. Lichtenstein D, Mezière G, Seitz J. The dynamic air bronchogram. A lung ultrasound sign of alveolar consolidation ruling out atelectasis. Chest 2009;135(6): 1421-1425.

8. Berlet T, Etter R, Fehr T, Berger D, Sendi P, Merz TM. Sonographic patterns of lung consolidation in mechanically ventilated patients with and without ventilator-associated pneumonia: a prospective cohort study. J Crit Care 2015;30(2):327333.

9. Mongodi S, Bouhemad B, Orlando A, Stella A, Tavazzi G, Via G, et al. Modified lung ultrasound score for assessing and monitoring pulmonary aeration. Ultraschall Med 2017;38(5):530-537.

10. Jung B, Embriaco N, Roux F, Forel JM, Demory D, Allardet-Servent J, et al. Microbiogical data, but not procalcitonin im- prove the accuracy of the clinical pulmonary infection score. Intensive Care Med 2010;36(5):790-798.

11. Torres A, Niederman MS, Chastre J, Ewig S, Fernandez-Vandellos P, Hanberger H, et al. International ERS/ESICM/ESCMID/ALAT guidelines for the management of hospital-acquired pneumonia and ventilatorassociated pneumonia: guidelines for the management of hospital-acquired pneumonia (HAP)/ventilator-associated pneumonia (VAP) of the European Respiratory Society (ERS), European Society of Intensive Care Medicine (ESICM), European Society of Clinical Microbiology and Infectious Diseases (ESCMID) and Asociación Latinoamericana del Tórax (ALAT). Eur Respir J 2017;10:50(3). pii: 1700582.

\section{Driving Pressure or Tidal Pressure: What a Difference a Name Makes}

\section{To the Editor:}

In a recent article in this Journal, Baldomero et $\mathrm{al}^{1}$ provided, for the first time, data on actual ranges of driving pressure for a variety of patients during mechanical ventilation. This is a well-written and useful article, and our intent is not to criticize it but to point out how the common use of the term driving pressure may lead to confusion.

In the Quick Look section of the article, driving pressure $(\Delta \mathrm{P})$ is defined as "the difference between $\mathrm{P}_{\text {plat }}$ [plateau pressure] and end-expiratory pressures." ${ }^{1}$ This is not a generally true statement (despite
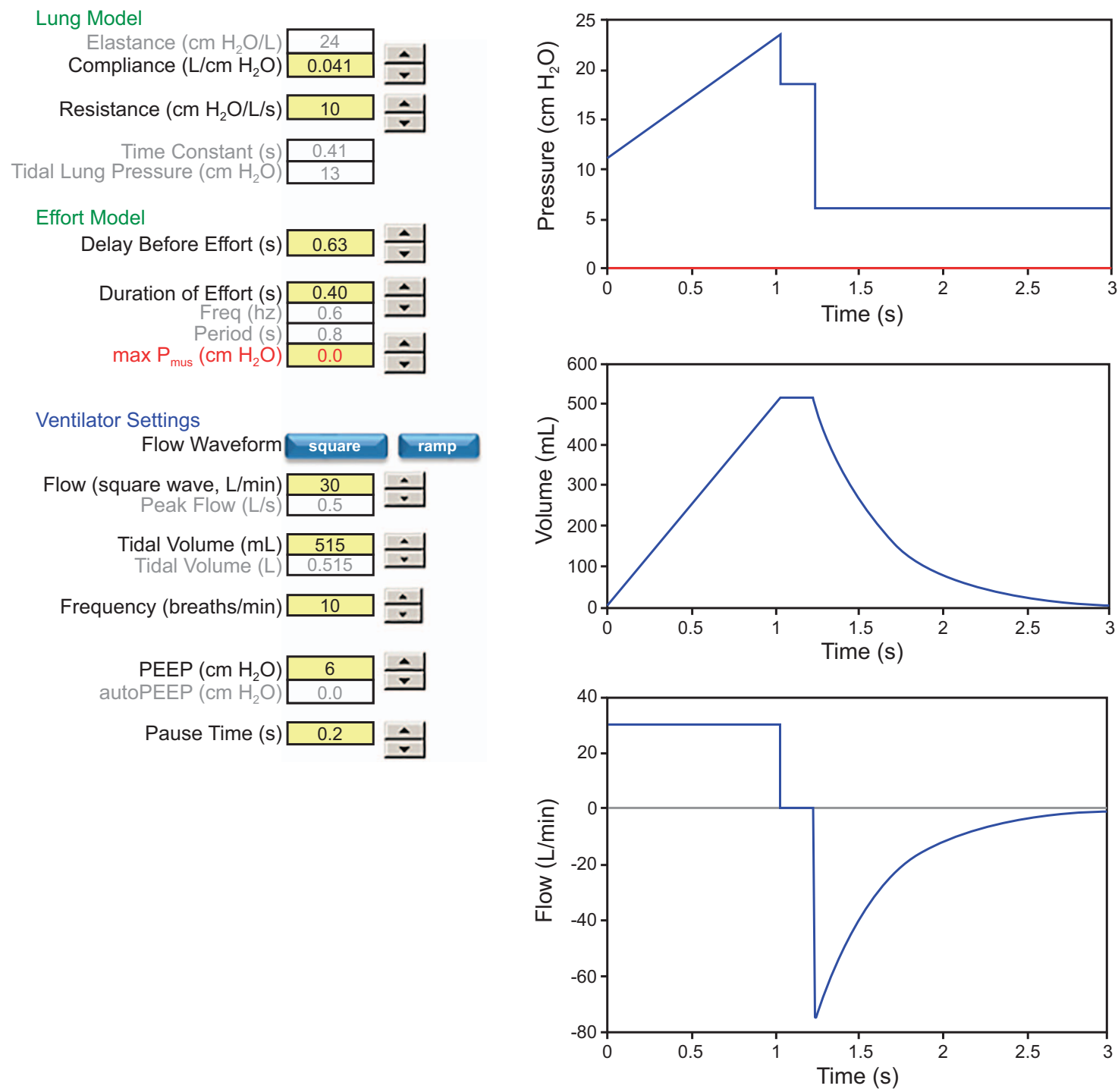

Fig. 1. Volume control breath with inspiratory hold, no inspiratory effort and no auto-PEEP. 


\section{CORRESPONDENCE}

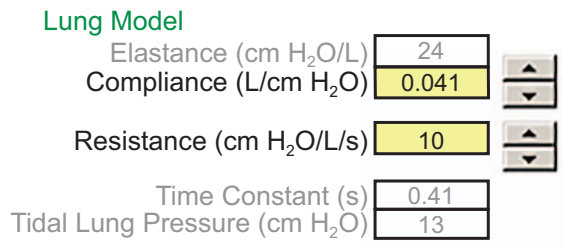

Effort Model

Delay Before Effort (s) $0.73 \div$

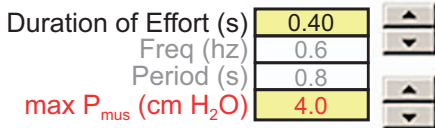

Ventilator Settings

Flow Waveform square ramp

Flow (square wave, L/min)
Peak Flow (L/s) 30

Tidal Volume $(\mathrm{mL}) \quad 515 \div$

Tidal Volume $(\mathrm{L}) \quad 0.515 \quad$

Frequency (breaths/min) 30

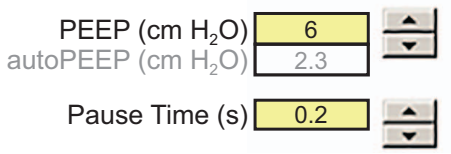

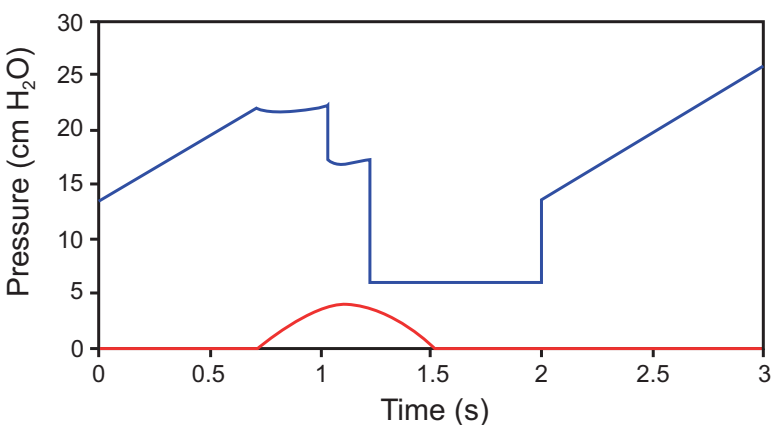
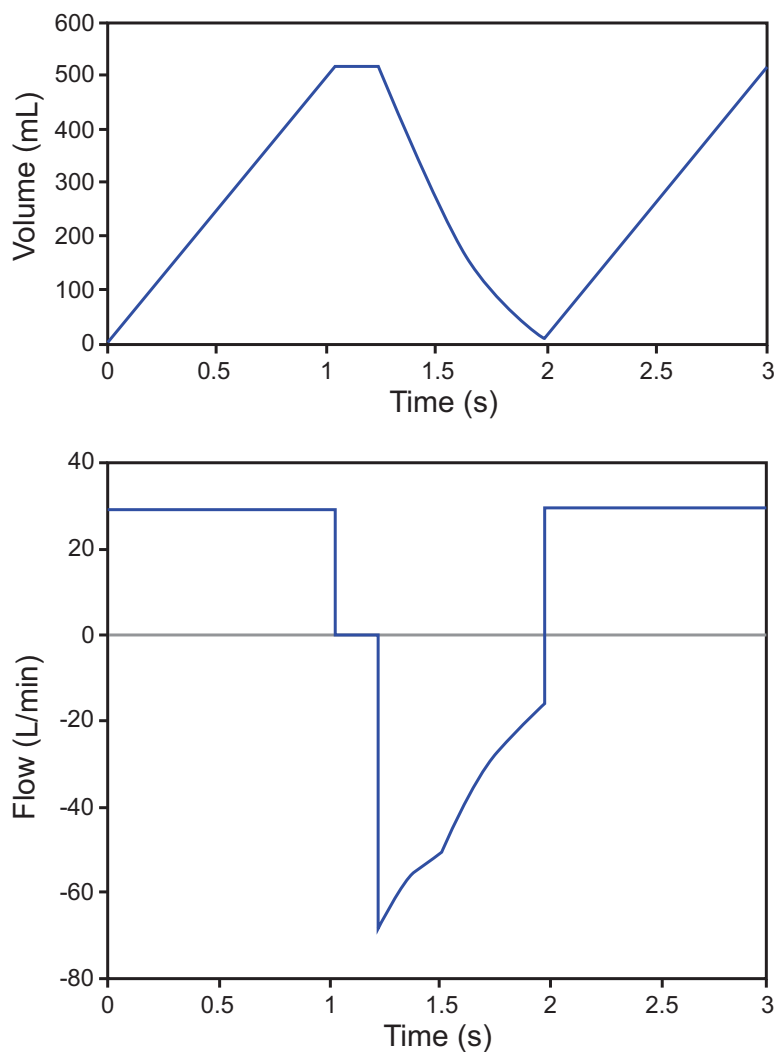

Fig. 2. Volume control breath with inspiratory hold, no auto-PEEP but with inspiratory effort of $4 \mathrm{~cm}_{2} \mathrm{O}$.

its common usage in the literature) because end-expiratory pressure must be measured under 2 specific conditions. One condition is the requirement for the absence of any inspiratory effort that could cause underestimation of $\mathrm{P}_{\text {plat }}$ (or overestimation if the patient actively exhales). The article's introduction includes this in its definition of $\Delta \mathrm{P}$ : "the difference between $\mathrm{P}_{\text {plat }}$ and end-expiratory airway pressures assessed under passive conditions ..." (emphasis ours) ${ }^{1}$; however, this definition fails to mention the other specific criterion, the requirement of a total PEEP measurement (total PEEP $=$ set
PEEP + auto-PEEP) by means of an endexpiratory hold. total $\mathrm{PEEP}=$ positive end expiratory pressure during an occlusion (aka, intrinsic PEEP), set PEEP = PEEP set on the ventilator, auto-PEEP = additional end expiratory pressure above set PEEP due to gas trapping (aka autoPEEP).

The authors, of course, understand the true definition, as indicated by the equation they describe in the Methods section: $\Delta \mathrm{P}=\left(\mathrm{P}_{\text {plat }}-\right.$ total PEEP $)$, and they explicitly note that "The algorithm of these ventilators for determining and displaying $\mathrm{P}_{\text {plat }}$ requires the absence of overt ef- fort or instability during end-inspiratory circuit occlusion, but it does not assure entirely passive inflation ..."1

These considerations indicate problems with the term $\Delta \mathrm{P}$. Confusion increases when talking about pressure control ventilation. ${ }^{2}$ For example, from the ventilator's point of view, driving pressure (ie, the pressure associated with inflation) could be $\Delta \mathrm{P}_{\text {elastic }}=$ elastance $\times \Delta$ volume, or $\Delta \mathrm{P}_{\text {resistive }}=$ resistance $\times$ flow, or $\Delta \mathrm{P}_{\text {total }}=$ $\Delta \mathrm{P}_{\text {elastic }}+\Delta \mathrm{P}_{\text {resistive }}$, where the $\Delta$ denotes a change in time for $\Delta \mathrm{P}_{\text {elastic }}$ and $\Delta \mathrm{P}_{\text {total, }}$ and a difference in space for $\Delta \mathrm{P}_{\text {resistive. }}$. From the patient's point of view, driving pressure 


\section{CORRESPONDENCE}

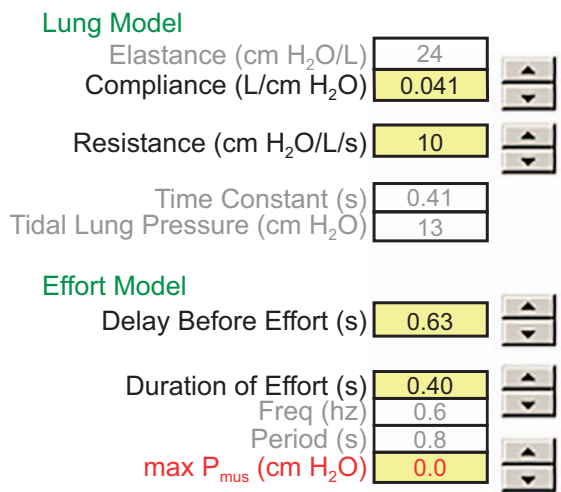

Ventilator Settings

\begin{tabular}{|c|c|c|}
\hline Flow Waveform & square & \\
\hline Flow (square wave, L/min) & 30 & - \\
\hline Peak Flow (L/s) & 0.5 & $\div$ \\
\hline Tidal Volume (mL) & 515 & 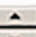 \\
\hline Tidal Volume (L) & 0.515 & $\checkmark$ \\
\hline Frequency (breaths/min) & 30 & $\stackrel{\Delta}{v}$ \\
\hline PEEP $\left(\mathrm{cm} \mathrm{H}_{2} \mathrm{O}\right)$ & 6 & $\stackrel{-}{7}$ \\
\hline autoPEEP $\left(\mathrm{cm} \mathrm{H}_{2} \mathrm{O}\right)$ & 2.3 & \\
\hline Pause Time (s) & 0.2 & $\Delta$ \\
\hline
\end{tabular}
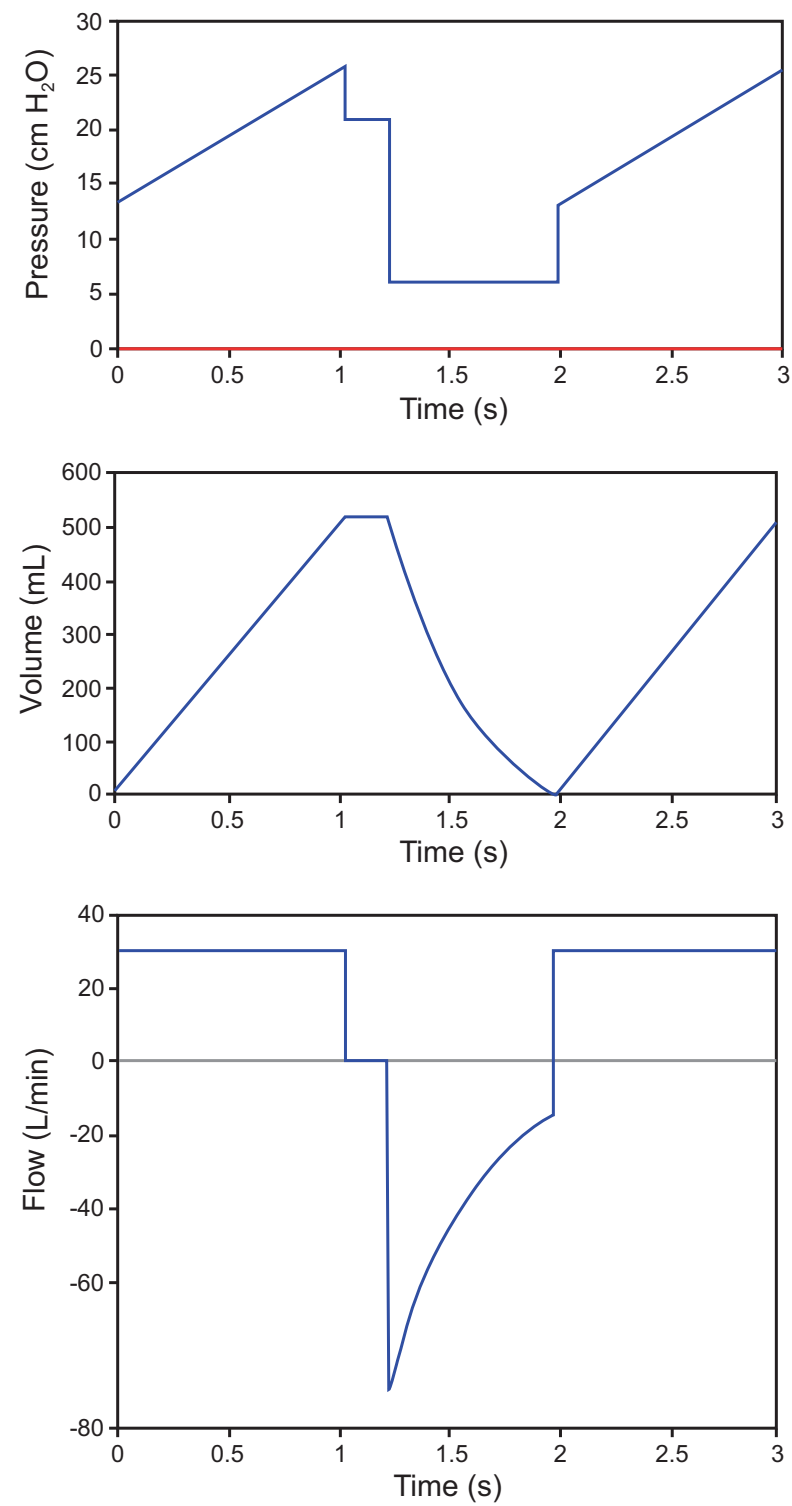

Fig. 3. Volume control with inspiratory hold, no inspiratory effort, but with $2.3 \mathrm{~cm} \mathrm{H}_{2} \mathrm{O}$ of auto-PEEP.

could be any form of pressure that is driving inspiration ${ }^{3}$ or the pressure that is driving expiration. In pressure control modes, clinicians often refer to inspiratory pressure above PEEP as the driving pressure ${ }^{4-8}$ perhaps because they see a constant inspiratory pressure and often assume that to be equal to $\mathrm{P}_{\text {plt }}$ (and set PEEP is equal to total PEEP). But this is only true if the inspiratory and expiratory time is long enough for inspiratory and expiratory flow to decay to zero.

There is a more subtle problem with $\Delta \mathrm{P}$ : what does the $\Delta$ stand for? The symbol itself is borrowed from mathematics and represents either a difference or a change in some variable. A difference in pressure can be between 2 points in space, as in the calculation of transrespiratory system pressure (eg, $\mathrm{P}_{\mathrm{TR}}=\mathrm{P}_{\mathrm{AO}}-\mathrm{P}_{\mathrm{BS}}$, where $\mathrm{AO}$ is airway opening and $\mathrm{BS}$ is body surface). A change in pressure can be measured at 2 points in time or a measurement made relative to a reference value (eg, pressure measured relative to atmospheric pressure, called gauge pressure). Driving pressure, as defined above, is actually a change in a pressure difference. The pressure difference is $\mathrm{P}_{\mathrm{TR}}$ (or alternatively transpulmonary pressure, $\mathrm{P}_{\text {tp }}=\mathrm{P}_{\mathrm{AO}}-\mathrm{P}_{\mathrm{PL}}$, where $\mathrm{P}_{\mathrm{PL}}$ is pleural pressure). The pressure change is $\mathrm{P}_{\mathrm{TR}}$ at end-inspiratory hold relative to $\mathrm{P}_{\mathrm{TR}}$ at endexpiratory hold.
All of this complexity vanishes if we simply use a different term, tidal pressure, $\mathrm{P}_{\mathrm{T}}$. Tidal pressure is related to tidal volume by the simple equation: $\mathrm{P}_{\mathrm{T}}=\mathrm{E} \times \mathrm{V}_{\mathrm{T}}$ or $\mathrm{P}_{\mathrm{T}}=$ $\mathrm{V}_{\mathrm{T}} / \mathrm{C}$, where $\mathrm{V}_{\mathrm{T}}$ is tidal volume, $\mathrm{E}=$ elastance, and $\mathrm{C}=$ compliance. This definition is independent of both inspiratory effort and auto-PEEP. It is interpreted the same as $\Delta \mathrm{P}$, the change in the pressure difference across the system required to deliver the $\mathrm{V}_{\mathrm{T}}$. The pressure difference can be either transrespiratory pressure or transpulmonary pressure.

To illustrate this, consider Figure 1, which shows the pressure, volume, and flow wave- 


\section{CORRESPONDENCE}

forms of a patient-ventilator simulator based on the equation of motion ${ }^{9}$ :

$$
\mathrm{P}_{\mathrm{AO}}+\mathrm{P}_{\mathrm{mus}}=\mathrm{V} / \mathrm{C}+\mathrm{R} \dot{\mathrm{V}}+\text { total PEEP }
$$

where $\mathrm{P}_{\mathrm{AO}}$ is gauge pressure at the airway opening (eg, the displayed pressure on a ventilator), $\mathrm{P}_{\text {mus }}=$ muscle pressure (ie, the force of inspiratory effort), $\mathrm{C}$ is compliance, $\mathrm{V}$ is volume, $\dot{\mathrm{V}}$ is flow, and total PEEP is end-expiratory airway pressure during an expiratory hold. The simulator is set with respiratory system mechanics similar to those reported in the article by Baldomero et al. ${ }^{1}$ There is no auto-PEEP and no inspiratory effort $\left(\mathrm{P}_{\text {mus }}=0\right)$. In Figure $1, \Delta \mathrm{P}=\mathrm{P}_{\text {plat }}$ $\mathrm{PEEP}=18.6-6=12.6 \mathrm{~cm} \mathrm{H}_{2} \mathrm{O}$. This is the same value as $\mathrm{P}_{\mathrm{T}}=\mathrm{V}_{\mathrm{T}} / \mathrm{C}=515 / 41=$ $12.6 \mathrm{~cm} \mathrm{H}_{2} \mathrm{O}$.

Shown in Figure 2 is the same model as in Figure 1 except with an inspiratory effort late in the inspiratory phase (eg, reverse triggering ${ }^{10}$ ), which decreases the $\mathrm{P}_{\text {plat }}$. Now $\Delta \mathrm{P}=\mathrm{P}_{\text {plat }}-\mathrm{PEEP}=16.9-6=10.9 \mathrm{~cm}$ $\mathrm{H}_{2} \mathrm{O}$. However, tidal pressure has not changed: $\mathrm{P}_{\mathrm{T}}=\mathrm{V}_{\mathrm{T}} / \mathrm{C}=515 / 41=12.6 \mathrm{~cm}$ $\mathrm{H}_{2} \mathrm{O}$.

Shown in Figure 3 is the same model as in Figure 1 except with a higher ventilator frequency, which causes a auto-PEEP level of $2.3 \mathrm{~cm} \mathrm{H}_{2} \mathrm{O}$. The $\Delta \mathrm{P}=\mathrm{P}_{\text {plat }}-\mathrm{PEEP}=$ $20.8-6=14.8 \mathrm{~cm} \mathrm{H}_{2} \mathrm{O}$. But again, tidal pressure has not changed: $\mathrm{P}_{\mathrm{T}}=\mathrm{V}_{\mathrm{T}} / \mathrm{C}=$ $515 / 41=12.6 \mathrm{~cm} \mathrm{H}_{2} \mathrm{O}$.

These results are summarized in Table 1. It shows that, under ideal conditions (passive inflation and no auto-PEEP), $\Delta \mathrm{P}$ is equivalent to $\mathrm{P}_{\mathrm{T}}$. But, with inspiratory effort, $\Delta \mathrm{P}$ underestimates $\mathrm{P}_{\mathrm{T}}$; with auto-PEEP, $\Delta \mathrm{P}$ overestimates $\mathrm{P}_{\mathrm{T}}$.

One might argue that using $\mathrm{V}_{\mathrm{T}}$ is not really a simplification because $\mathrm{C}$ (or $\mathrm{E}$ ) must be calculated with the same caveats (ie, passive conditions and regard for auto-PEEP), as indicated in the Methods section of the article by Baldomero et al. ${ }^{1}$ However, C (or E) can be estimated without an inspiratory hold maneuver during inspiratory flow by fitting pressure, volume, and flow data points to the equation of motion by using linear regression. ${ }^{11}$ Indeed, the ventilator used in the study by Baldomero et $\mathrm{al}^{1}$ can do this (ie, dynamic vs static mechanics). Hence, given only one automatic, maneuver-free estimation of mechanics, multiple, unambiguous de-
Table 1. Examples of How Driving Pressure Is Underestimated in the Presence of Inspiratory Effort and Overestimated If Auto-PEEP Is Not Considered; These Factors Do Not Affect Tidal Pressure

\begin{tabular}{rcc}
\hline \hline \multicolumn{1}{c}{ Factor } & $\mathrm{P}_{\mathrm{T}}$ & $\Delta \mathrm{P}$ \\
\hline $\mathrm{P}_{\text {mus }}=0$ & 12.6 & 12.6 \\
$\mathrm{P}_{\text {mus }}=4$ & 12.6 & 10.9 \\
Auto-PEEP $=0$ & 12.6 & 12.6 \\
Auto-PEEP $=2.3$ & 12.6 & 14.8
\end{tabular}

terminations of $\mathrm{P}_{\mathrm{T}}$ can be made over a relatively long period of ventilation.

In conclusion, the paper by Baldomero et $\mathrm{al}^{1}$ defines driving pressure as $\mathrm{P}_{\text {plat }}-$ total PEEP. This is not the same force that drives inspiratory or expiratory flow. On the contrary it is a different metric related to a different concern, ie, lung stretch, and not peak flow. Hence it deserves a different name. We suggest the name tidal pressure, $\mathrm{P}_{\mathrm{T}}$, defined as $\mathrm{V}_{\mathrm{T}} \times \mathrm{E}=\mathrm{V}_{\mathrm{T}} / \mathrm{C}=\mathrm{P}_{\text {plat }}-$ total PEEP. It follows that from the perspective of lung injury, the important concept is tidal pressure, not driving pressure. If we are going to adopt a new metric for use in monitoring the risk of ventilator induced lung injury, we should use a term for it that has the lowest chance of misunderstanding. In that regard, tidal pressure is preferable to driving pressure.

\section{Robert L Chatburn \\ Respiratory Institute Cleveland Clinic Cleveland, Ohio}

Matthias van der Staay Department of Engineering IMT AG

Buchs, Switzerland

\section{REFERENCES}

1. Baldomero AK, Skarda PK, Marini JJ. Driving pressure: defining the range. Respir Care 2019;64(8):883-889.

2. Chatburn RL, Volsko TA. Documentation issues for mechanical ventilation in pressure-control modes. Respir Care 2010; 55(12):1705-1716.

3. Branson R. Understanding and implementing advances in ventilator capabilities. Curr Opin Crit Care 2004;10(1):23-32.
4. Baldoli I, Cuttano A, Scaramuzzo RT, Tognarelli S, Ciantelli M, Cecchi F, et al. A novel simulator for mechanical ventilation in newborns: MEchatronic REspiratory System SImulator for Neonatal Applications. Proc Inst Mech Eng H 2015; 229(8):581-591.

5. Chiu LC, Hu HC, Hung CY, Chang $\mathrm{CH}$, Tsai FC, Yang CT, et al. Dynamic driving pressure associated mortality in acute respiratory distress syndrome with extracorporeal membrane oxygenation. Ann Intensive Care 2017;7(1):12.

6. Peterson-Carmichael S, Seddon PC, Cheifetz IM, Frerichs I, Hall GL, Hammer J, et al; ATS/ERS Working Group on Infant and Young Children Pulmonary Function Testing. An Official American Thoracic Society/ European Respiratory Society Workshop Report: evaluation of respiratory mechanics and function in the pediatric and neonatal intensive care units. Ann Am Thorac Soc 2016; 13(2):S1-S11.

7. Bhutani VK, Sivieri EM. Clinical use of pulmonary mechanics and waveform graphics. Clin Perinatol 2001;28(3):487-503, v.

8. Ashworth L, Norisue Y, Koster M, Anderson J, Takada J, Ebisu H. Clinical management of pressure control ventilation: an algorithmic method of patient ventilatory management to address "forgotten but important variables". J Crit Care 2018;43:169-182.

9. Crooke PS, Head JD, Marini JJ, Hotchkiss JR. Patient-ventilator interaction: a general model for nonpassive mechanical ventilation. IMA J Math Appl Med Biol 1998; 15(4):321-337.

10. Akoumianaki E, Lyazidi A, Rey N, Matamis D, Perez-Martinez N, Giraud R, et al. Mechanical ventilation-induced reversetriggered breaths: a frequently unrecognized form of neuromechanical coupling. Chest 2013;143(4):927-938.

11. Polak AG. Analysis of multiple linear regression algorithms used for respiratory mechanics monitoring during artificial ventilation. Comput Methods Programs Biomed 2011;101(2):126-134.

Mr Chatburn discloses relationships with imtmedical AG, IngMar Medical, and Drive DeVilbiss Healthcare. Mr van der Staay is an employee of IMT AG.

Correspondence: Robert L Chatburn MHHS RRT RRT-NPS FAARC, Respiratory Therapy Department - M56, Cleveland Clinic, 9500 Euclid Ave, Cleveland, OH 44195. E-mail: chatbur@ccf.org.

DOI: $10.4187 /$ respcare. 07233 